\title{
2 Regional Variation in EU Identification in the Southern and Eastern Peripheries of Europe: Does Cohesion Policy Matter?
}

\author{
Marcin Dąbrowski, Dominic Stead, Bardia Mashhoodi ${ }^{3}$
}

\begin{abstract}
EU cohesion policy, supporting a variety of projects that support regional economic development and contribute to betterment of quality of life, can be considered as a tool that is contributing to the development of a 'sense of community' among the EU citizens and shaping the perceptions of the EU. By investing in projects across the European territory, the policy has a direct impact on people's daily lives and their environment. Whether and how exactly EU cohesion policy actually affects what people think about the EU remains unclear, particularly at the regional level where the policy has the most direct and palpable effects. The chapter addresses this knowledge gap by exploring the regional variation of EU identification across the regions of southern and eastern Europe. This focus is particularly relevant given that these countries are the main beneficiaries of EU cohesion policy. At the same time, many of these countries are experiencing tumultuous political developments tilting the governmental discourse towards sceptical or even hostile positions towards European integration, which is not necessarily in line with citizens' views on the EU. The study uses Euro-barometer surveys from 2015 to explore how opinions about EU image and attachment to EU vary across southern and eastern Europe. The analysis identifies clusters of regions with similar patterns and then tries to relate these clusters to the possible role of cohesion policy in the emergence of these regional patterns.
\end{abstract}

Keywords: European Union; identification; attachment; regions; citizens; Southern Europe; Eastern Europe.

\subsection{Introduction}

The European Union (EU) has been battered by a series of crises since the late 2000s: from the global economic crisis and its European aftershocks, to the Eurozone crisis, and from the migration crisis, to the rise of the anti-European populist movements. As a result, the tone of public debate on the EU has become more critical and pessimistic, denting support for European integration among citizens. Reflecting these shifts,

3 Department of Urbanism, Faculty of Architecture and the Built Environment, Delft University of Technology,Julianalaan134,2628BLDelft,The Netherlands.Correspondence:m.m.dabrowski@tudelft.nl

Ә Open Access. ( 2020 Ida Musiatkowska, Piotr Idczak, Oto Potluka and chapters' contributors. Published by De Gruyter. (c) BY-NC-ND This work is licensed under the Creative Commons Attribution-NonCommercial-NoDerivs 3.0 License. https://doi.org/10.1515/9788395720451-003 
the discourse on cohesion policy has also evolved from an emphasis on the need to reduce territorial disparities across the EU towards an emphasis on the improvement of daily lives for all EU citizens.

Shortly after the 'big bang' Eastward enlargement of the EU, the then Commissioner for Regional Policy, Danuta Hübner, argued that "cohesion policy aims to facilitate structural change throughout Europe, and to enable regions to respond more effectively to the opportunities generated by the world's largest single market [...] We cannot afford to leave behind even the smallest region. All of them should contribute to raising Europe's growth and competitiveness." More recently, in the post-crisis context, the discourse shifted dramatically, as illustrated by this quote from a speech by Commissioner Corina Creţu from 2017:

[C]ohesion policy is the most visible, the most tangible illustration of a caring Europe. It improves the daily lives of all citizens, wherever they live [...]. Cohesion policy is the cement that holds Europe together, because it cares for individuals, because its aim is to improve everybody's life. ${ }^{4}$

Corina Creţu, 2017

Echoing the discursive shift, the EU increased its efforts to make EU cohesion policy more visible to citizens, not least to counteract the declining support for European integration and combating the rise of anti-EU populism. For instance, in 2017, the Council of the EU adopted conclusions on "making Cohesion policy more effective, relevant and visible to our citizens," 5 while the European Parliament urged for greater visibility of cohesion policy "to fight against Euroscepticism" and "contribute to regaining citizens' confidence and trust." 6

The actual impact of cohesion policy on citizens' attitudes towards the EU remains unclear and contested. Early research by Duch and Taylor (1997) on this topic found that cohesion policy transfers did not translate into increased support for European integration, with the poorer regions benefiting from more substantial transfers remaining less 'euro-enthusiastic,' even if the data for this study predated the actual establishment of cohesion policy in 1988. In contrast, later studies painted an ambiguous picture. Positive effects of the size of allocation of structural funds on public support for the EU were found, albeit mediated by the degree of awareness of the EU funding, which in turn was related to the level of education (Osterloh, 2011). A more recent study found that there was no direct link between the size of European

\footnotetext{
4 Commissioner Corina Creţu's speech in Molenbeek, Belgium, 6 June 2017: https://ec.europa. eu/commission/commissioners/2014-2019/cretu/announcements/speech-commissioner-cretumolenbeek_en

5 "Making Cohesion Policy more effective, relevant and visible to our citizens", 8463/17, adopted by the Council of the EU on 25 May 2017.

6 "Report on Building Blocks for a Post-2020 EU Cohesion Policy”, 2016/2326(INI), European Parliament, 24 May 2017.
} 
Regional Development Fund allocation and EU support, and that the effect of this funding was, at best, conditional upon pre-existing EU identification and education levels (Chalmers \& Dellmuth, 2015).

More importantly, cohesion policy offers support for regional development and is, to a large extent, managed and implemented at the regional level, with varying sizes of allocation, governance approaches, thematic focus of spending, absorption rates and effectiveness. Consequently, one may expect differentiation in the impacts of cohesion policy on the citizen's attitudes vis-à-vis the EU across different regional settings. Before one considers whether and how cohesion policy affects EU identification, therefore, we need a clearer understanding of the regional dimension of that phenomenon, while most studies and surveys on EU identity to date tend to focus on the national level.

Before unpacking EU identification at the regional level, the nature of the concept is briefly outlined. Broadly, scholars investigating the notion tend to consider three dimensions of EU identification: (i) cognitive; (ii) evaluative; and (iii) affective (for a review, see for example Mendez \& Bachtler, 2016). The cognitive dimension refers to the perception of one's self as European. The evaluative aspect refers to the more 'utilitarian' dimension of support based on the perceived benefits stemming from European integration. Finally, the affective dimension corresponds to the 'we-feeling,' or feelings of belonging to a (European) community.

What factors can shape EU identification along those two dimensions? Can EU cohesion policy be an important factor? The evaluative dimension of EU identification can in fact be related to EU policies that have a direct impact on citizens' lives. The most prominent example of this could indeed be cohesion policy, supporting a variety of projects that support regional economic development and contribute to betterment of quality of life. Investments in regions, where the project sites are marked with banners with EU flags and acknowledgement of EU funding, are perhaps the most visible and physical manifestation of benefits that the EU can bring to citizens' daily lives and their immediate living environment. At the same time however, EU cohesion policy can be considered as a tool that is contributing to the development of a 'sense of community' among the EU citizens and thus shaping the affective aspect of EU identification. Even so, whether and how exactly EU cohesion policy actually affects what people think about the EU remains unclear, particularly at the regional level where the policy has the most direct and palpable effects.

Clearly, cohesion policy is just one among many other EU policies and rules that may have an impact on EU identification. A few examples of other EU policies and rules are briefly illustrated here. First, the Common Market and its freedom of movement of people and labour, which offers unprecedented opportunities for mobility, tourism, and improvement of living conditions through working and living in another EU country, could potentially have impacts both on the affective and evaluative dimensions of EU identification. Second, the Erasmus programme, which supports student mobility and gives its beneficiaries often a first experience of 
learning, socialising, and living in a different European country at a critical formative period of life, could have impacts on the affective dimension of EU identification. Third, EU regulations related to cellular phone roaming charges within the EU, allowing citizens to pay the same rate for mobile telecommunication services across the EU as they do in their home country, is a material benefit for citizens that may influence the evaluative dimension of identification.

Meanwhile, the EU's actions, and developments related to it, may also have negative impacts on how the citizens identify with it. Here, the most prominent example is the territorially uneven impact of the global economic crisis and the subsequent sovereign debt crisis and austerity measures in the Eurozone, affecting mostly the Southern Member States and especially the less resilient regions within them-as was the case in Greece, for instance (Yannis, Dimitris, \& Panagiotis, 2014). EU image in the areas most affected by these developments, such as Greece, has severely deteriorated, as evidenced by the raise of Eurosceptic populist movements across European regions (Dijkstra et al. 2019, Smętkowski \& Dąbrowski, 2019).

The strength of the influence of many of the above actions on citizens' identification is very likely to be differentiated across the European member states and, critically, across territories. It might be expected that cohesion policy could have the most impact on what people think about the EU in the less developed regions that receive substantial allocations of European Structural and Investment Funds (ESIF), mainly concentrated in the Southern and Eastern EU Member States. At the same time, the negative effects of the economic post-2008 meltdown and the Eurozone crisis (with the subsequent EU-induced austerity measures), as well as of the migration crisis, are also felt more in certain regions, depending on their socio-economic situation and location on or off the main migration routes from the Middle East or Africa.

This chapter explores and classifies EU identification at the regional level. In other words, it seeks to shed light on how identification varies across the regions of the EU's 28 Member States and to identify the patterns in this variation. The study draws on the H2020 COHESIFY ${ }^{7}$ project and uses Eurobarometer surveys as a source of data for the analysis. The typology of regional EU identification produced by this research offers a more nuanced view than in most studies on EU identification focusing on national level by: (1) investigating, for the first time how citizens view the EU at the regional level in a post-crisis context, and (2) by bringing together the two perspectives on EU identification, the evaluative (rationalist) perspective and the affective one. Beyond this, the typology allows for comparing EU identification patterns across European regions. This allows for pondering the extent to which positive identification with the EU is predominant in regions that have been the biggest beneficiaries of cohesion

7 The Horizon 2020 COHESIFY project investigated how EU identification varies across the differentiated regional contexts of the $28 \mathrm{EU}$ member states. For more information see www.cohesify. eu. 
policy, either in the past or at present. An important caveat is that, in this study, we do not carry out statistical analysis on the linkages between the EU identification types and EU cohesion policy variables, such as size of allocation, thematic focus of spending, or absorption rate. This is an obvious limitation of this research, pointing to the need for further research.

The chapter is divided into four parts. The next part outlines the conceptual framework for the research, drawing on the different dimensions of EU identification as conceptualised in the literature. Then, the analytical methods used are briefly outlined. The subsequent part of the chapter presents the results discusses their implications. The chapter closes with concluding observations together with an outline of additional research questions that the results open up.

\subsection{EU Identification: What Determines it and Why Do We Expect Cohesion Policy to Matter?}

A range of literature sources provides some clues about the factors that may shape identification with the EU among citizens. Some of these may be related to the costs and benefits associated with European integration, whereby the winners of this process are more likely to view the EU in a positive light than those who lose out from this process (Bellucci, Sanders, \& Serricchio, 2012; Fligstein, 2008; 2009). Against this background, it is not surprising that studies covering the period of late 1990s, when cohesion spending was increasing, indicated a positive impact of Structural Funds on the positive perceptions of the EU (Brinegar, Jolly, \& Kitschelt, 2004; Osterloh, 2011), particularly among the direct recipients of funding. Previous research has shown that an increase of per capita transfer from the EU to a region by 100 Euro boosts the likelihood of one being positive about the EU by approximately 5 to 15\% (Osterloh, 2011).

Beyond the size of the allocation of EU funds for a particular territory, another factor behind EU identification among citizens are transnational experiences and social interactions across borders. Previous research indicates that such interactions across borders can positively affect identification with the EU (Bellucci et al., 2012; Fligstein, 2009). One can thus assume that EU cohesion policy funding for territorial cooperation could be a factor facilitating such transnational experiences and, hence, boosting positive views on the EU. This can be particularly relevant in the case of cross-border cooperation programmes offering arguably most tangible opportunities to interact with the neighbouring region-as opposed to less tangible transnational or macro-regional programmes of territorial cooperation covering larger territories.

Other factors behind EU identification among citizens relate less directly to cohesion policy. There are studies that indicate that the strength of pre-existing territorial identities at national or sub-national level also affects, either positively or negatively, European identification (Bruter, 2009; Chacha, 2013; Duchesne \& 
Frognier, 1995; Hooghe \& Marks, 2003; Marks, 1999; Medrano \& Gutiérrez, 2001). These identities are deeply rooted in long-standing nation-building, sociological, and geopolitical processes that go far beyond the time horizon of cohesion policy (which was established in 1988). Another factor, equally deeply rooted in socio-institutional legacies of specific territories, is the degree of trust in national political institutions that the citizens have. When trust in national institutions is low, then the trust in the EU tends to be higher, as it provides alternative-arguably, less corrupt-locus of identification to citizens disgruntled by their governments (Bellucci et al., 2012). Finally, literature on 'cognitive mobilisation' suggests that socio-demographic characteristics may also play a role in determining positive identification with the EU, with key factors favouring it being higher income, occupational status, and educational attainment (Citrin \& Sides, 2004; Duchesne \& Frognier, 1995; Fligstein, 2009; Medrano \& Gutiérrez, 2001). These findings seem to be related to those from studies on the Structural Funds impacts indicating that awareness of EU funding is related to socio-economic background and translated into support for the EU(Osterloh, 2011); and that education level plays a mediating role in the effect of EU transfers on the perceptions of the European integration project (Chalmers \& Dellmuth, 2015). Thus, citizens in poorer regions, where education levels are relatively low, may be less aware of EU funding invested in their surroundings and hence less likely to have positive views on the EU.

\subsection{Data and Methodology}

A typology of EU identification is constructed in this chapter with the focus on Southern and Eastern regions of the EU, the main recipients of cohesion policy funding. The typology is used to examine whether the amount of regional development funding is related to how positive citizens feel about the EU. The research draws on data from Standard Eurobarometer surveys from 2015 to describe and compare the differences in attitudes to EU identification across Europe. Two sorts of questions from the Eurobarometer surveys were used to construct a typology of EU identification. The first of these questions relates to public opinions about EU's image ${ }^{8}$; the second relates to attachment to it ${ }^{9}$. These two variables correspond well to the two dimensions of EU identification: EU image variable, or probing the citizens' general impression of the

\footnotetext{
8 The question about EU image is typically phrased (in the local language) as follows: "In general, does the EU conjure up for you a very positive, fairly positive, neutral, fairly negative or very negative image?"

9 The question about EU attachment is typically phrased (in the local language) as follows: "Please tell me how attached you feel to the European Union (very attached, fairly attached, not very attached, not at all attached)."
} 
EU, reflects well the evaluative dimension (How well does the EU work for me? How much do I benefit from it?), while the attachment variable, or probing the intensity of positive feelings towards the EU, allows for measuring the affective dimension (How do I feel towards the EU?). In this study, the cognitive dimension of EU identification is not considered, focusing only on the evaluative and affective dimensions.

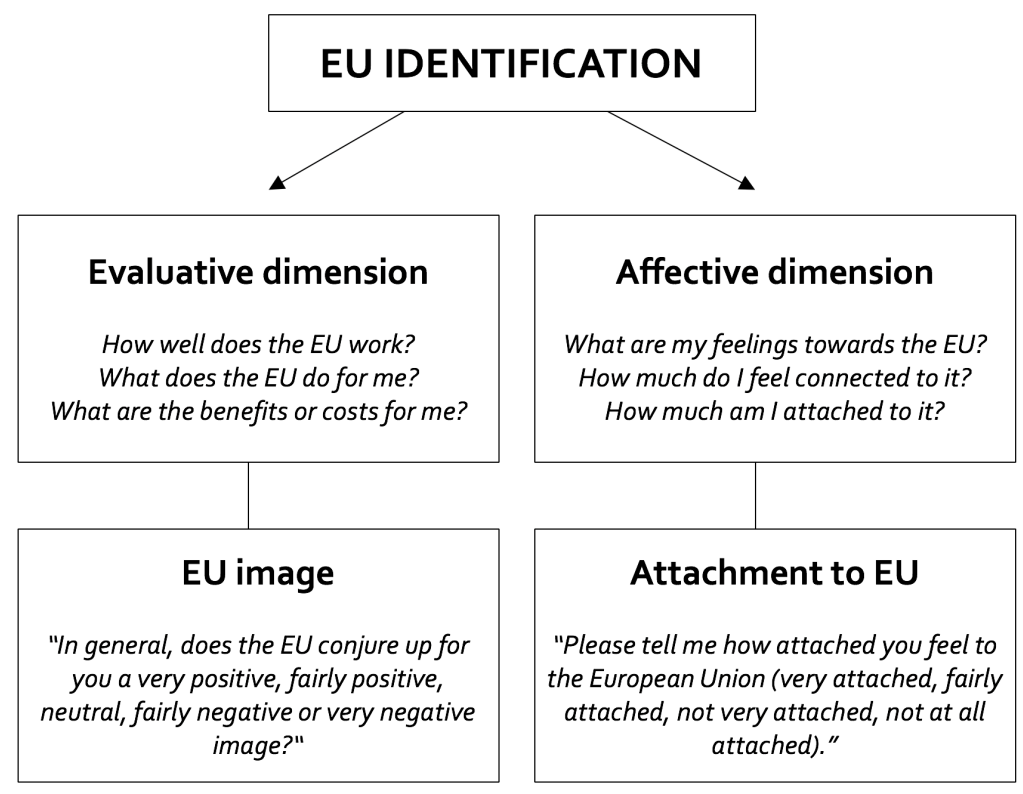

Figure 1: Dimensions of EU identification and variables used to measure them.

Source: Own elaboration, variables and the related survey questions adapted from Eurobarometer.

Although questions concerning the EU's image appear regularly in Eurobarometer surveys, fewer waves contain questions on attachment to the European Union. For the purpose of the typology developed in this study, regionally coded waves of the Eurobarometer survey from 2015 were used (see table 1).

\begin{tabular}{ll}
\hline Surveys used & Variables \\
\hline Eurobarometer 84.4 November - December 2015 & EU image \\
Eurobarometer 84.3 November 2015 & EU image and attachment to the EU \\
Eurobarometer 84.1 September 2015 & EU image and attachment to the EU \\
\hline
\end{tabular}


In order to construct a composite typology of EU identification, hierarchical cluster analysis was used to identify groupings of EU image and attachment across 258 NUTS 2 regions for which data was available. Cluster analysis is a method that allows for exploring complex data sets in search for homogenous grouping of objects based on multivariate similarity (see for example Gore Jr., 2000). The analysis is widely used across various disciplines to build classification systems or typologies. The hierarchical method for cluster analysis allows for identifying a hierarchy of nested clusters that can be represented graphically in a tree structure. In this particular case, a decision was made to identify five clusters, striking a balance between the accuracy of clustering and legibility of the typology.

As with all research methods, there are certain limitations which need to be acknowledged. First, while offering a useful categorisation along the relevant variables, the typology is based on inevitably arbitrary decisions that had to be made to define the boundaries between the types. This invites caution in interpreting the differences between the types. Second, there are limitations stemming from the dataset. In Eurobarometer surveys, the number of respondents in particular regions may be relatively small, which limits the validity of the data on the regional scale. To mitigate this limitation, several waves of Eurobarometer surveys were combined from the same year (2015) to increase the sample size and validity. Finally, our analysis focuses on a single year, compiling several surveys from 2015, and therefore cannot account for change of EU identification in regions over time. It should also be noted at this point that some caution is required when interpreting the typology since it is not based on extensive statistical analysis over time and does not explore the role of other factors shaping EU identification mentioned above, such as education levels or socio-economic situation of citizens.

\subsection{Results}

Five clusters of regions were identified using hierarchical cluster analysis:

1.1. "Positive on both counts" (positive-attached): Regions in which opinions among citizens are higher than average about the image of the EU and attachment to it.

2.1. "Neutral EU image but still attached" (neutral-attached): Regions in which the image of the EU is neutral among citizens but attachment to the EU is above average.

2.2. "Neutral on both counts" (neutral-neutral): Regions in which the image of the EU is moderate (or neutral) among citizens, as is attachment to the EU.

3.1. "Negative image but still attached" (negative-attached): Regions in which the image of the EU is predominantly negative among citizens but they nevertheless feel some attachment to the EU. 
3.2. "Negative image and half attached" (negative-neutral): Regions in which the image of the EU is predominantly negative among citizens and feelings of attachment are neutral.

The main characteristics of these clusters are summarised in Table 2. Figure 3 shows the distribution of the types across the EU, while Figure 4 indicates the Southern and Eastern European regions that are the focus of this chapter.

Table 2: Characteristics of the five types of regions according to citizens' opinions on the image of the EU and attachment to it.

\begin{tabular}{|c|c|c|c|c|c|}
\hline & Cluster 1.1 & Cluster 2.1 & Cluster 2.2 & Cluster 3.1 & Cluster 3.2 \\
\hline & $\begin{array}{l}\text { "Positive on } \\
\text { both counts" } \\
\text { (positive- } \\
\text { attached }\end{array}$ & $\begin{array}{l}\text { "Neutral EU } \\
\text { image but } \\
\text { still attached" } \\
\text { (neutral- } \\
\text { attached) }\end{array}$ & $\begin{array}{l}\text { "Neutral on } \\
\text { both counts" } \\
\text { (neutral- } \\
\text { neutral) }\end{array}$ & $\begin{array}{l}\text { "Negative } \\
\text { image but } \\
\text { still attached" } \\
\text { (negative- } \\
\text { attached) }\end{array}$ & $\begin{array}{l}\text { "Negative } \\
\text { image and } \\
\text { half attached" } \\
\text { (negative- } \\
\text { neutral) }\end{array}$ \\
\hline Number of regions & 35 & 86 & 57 & 56 & 24 \\
\hline Proportion of regions & $13.6 \%$ & $33.3 \%$ & $22 \%$ & $22 \%$ & $9 \%$ \\
\hline \multicolumn{6}{|c|}{ Image of the EU among citizens } \\
\hline$\%$ positive & $47 \%$ & $35 \%$ & $35 \%$ & $23 \%$ & $23 \%$ \\
\hline$\%$ neutral & $39 \%$ & $41 \%$ & $41 \%$ & $37 \%$ & $37 \%$ \\
\hline$\%$ negative & $9 \%$ & $21 \%$ & $21 \%$ & $36 \%$ & $36 \%$ \\
\hline \multicolumn{6}{|c|}{ Citizens' attachment to EU } \\
\hline$\%$ attached & $63 \%$ & $55 \%$ & $42 \%$ & $40 \%$ & $30 \%$ \\
\hline$\%$ neutral & $24 \%$ & $31 \%$ & $37 \%$ & $34 \%$ & $41 \%$ \\
\hline$\%$ unattached & $9 \%$ & $10 \%$ & $17 \%$ & $22 \%$ & $26 \%$ \\
\hline
\end{tabular}

Source: Own elaboration on the basis of Eurobarometer data.

\subsection{Discussion}

The first striking observation from the typology is that there are no regions with a predominantly negative image of the EU and no attachment to the EU. Thus, citizens tend to be attached to or at least neutral towards the EU even if they disapprove of what it does. In other words, the affective aspects of EU identification are more deeply rooted and stronger than the utilitarian aspects. As illustrated in figures 5 and 6, among Southern and Eastern European regions the types with more positive 


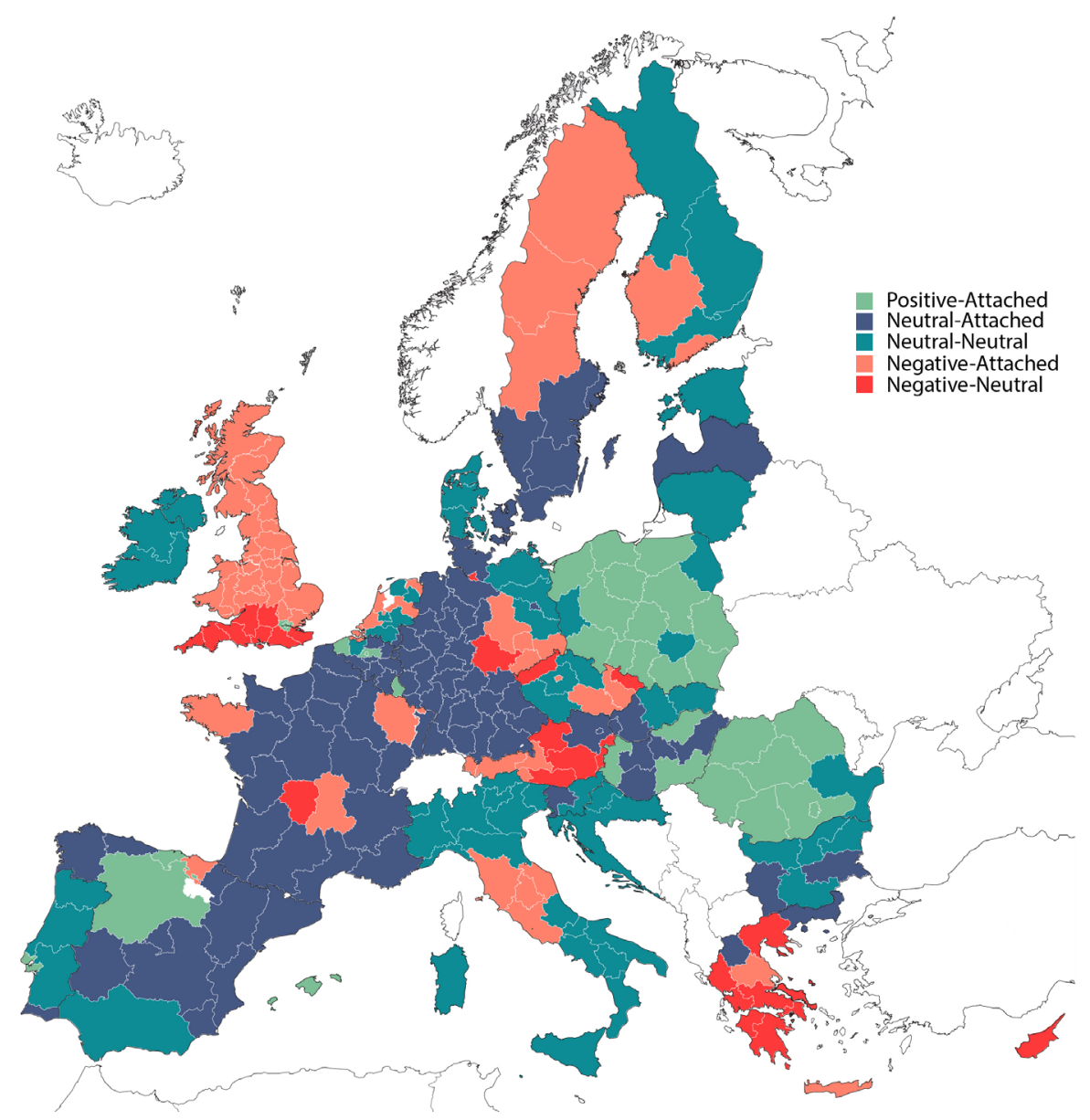

Figure 3: EU identification typology map - EU28.

Source: Own elaboration on the basis of Eurobarometer data.

EU identification, particularly in terms of EU image, tend to be predominant, as compared to the all EU28 regions. It is also striking, that the positive-positive type corresponds to as much as $26 \%$ of Southern and Eastern regions, as compared to $14 \%$ for the whole EU. Conversely, there are fewer regions in the types with predominantly negative EU image (negative-neutral and negative-attached) in Southern and Eastern Europe as compared to EU28. 


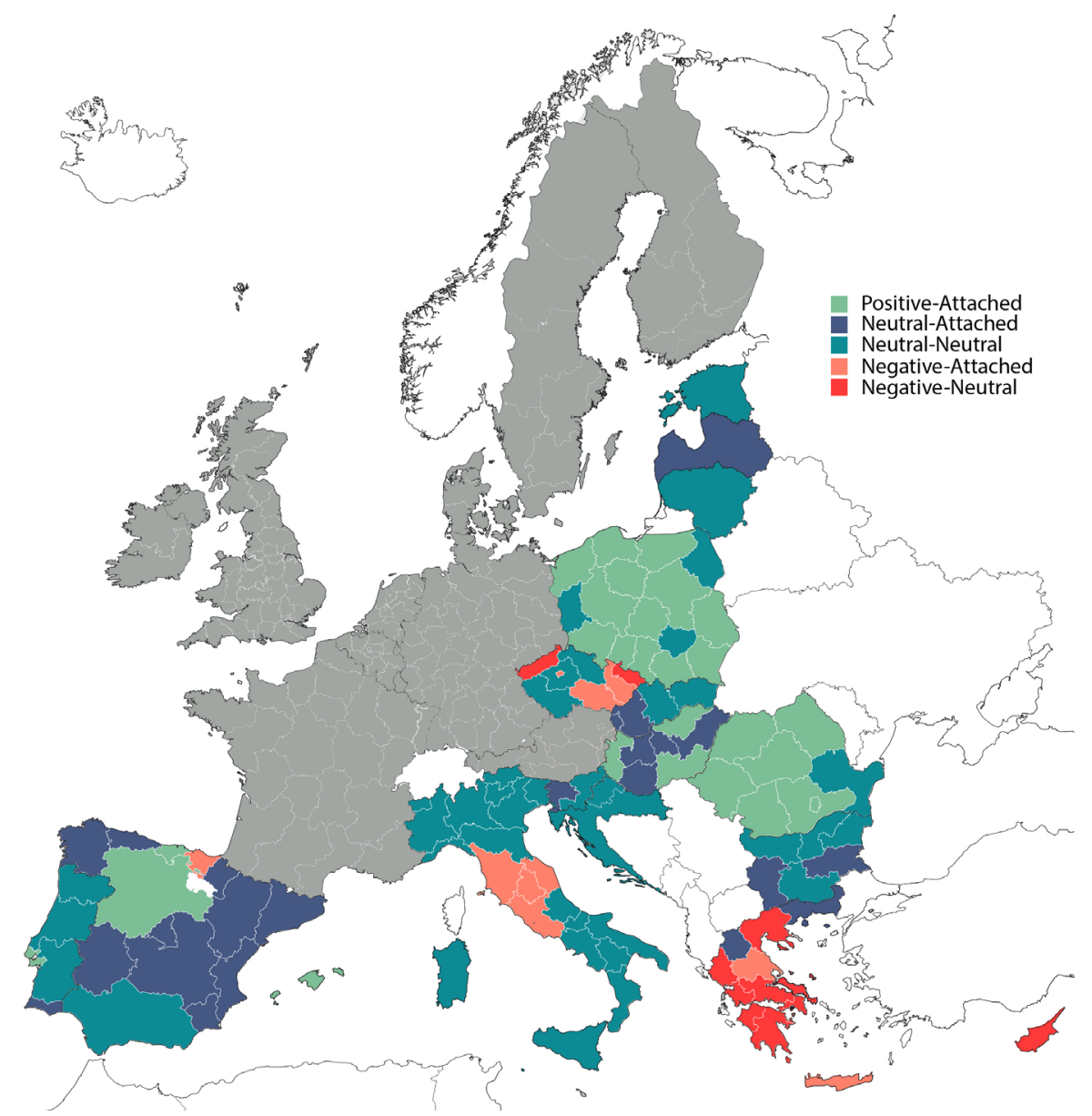

Figure 4: EU identification typology - Southern and Eastern European regions (focus of the analysis). Source: Own elaboration on the basis of Eurobarometer data.

Looking at the Southern member states (i.e. the countries that previously benefited from substantial allocations of EU Cohesion funds but have seen the amount of funding decline), there appears to be divergence between the regions of Italy, Spain, and Portugal, on the one hand, and the Greek regions and Cyprus, on the other hand. In the first group of countries, most regions belong to the neutral-attached, neutralneutral, or positive-attached types. The positive-attached type can be found in the Lisbon region in Portugal, and Castilla y Leon, Cantabria and the Balearic Islands in Spain. None of these regions are or were recently within a category of lagging regions receiving the highest allocations of EU Cohesion funding (i.e. none of them are within the 'Less developed regions' objective in 2014-2020 period, or the 'Convergence' objective in 2007-2013). The Italian and Spanish regions that have, or continue 


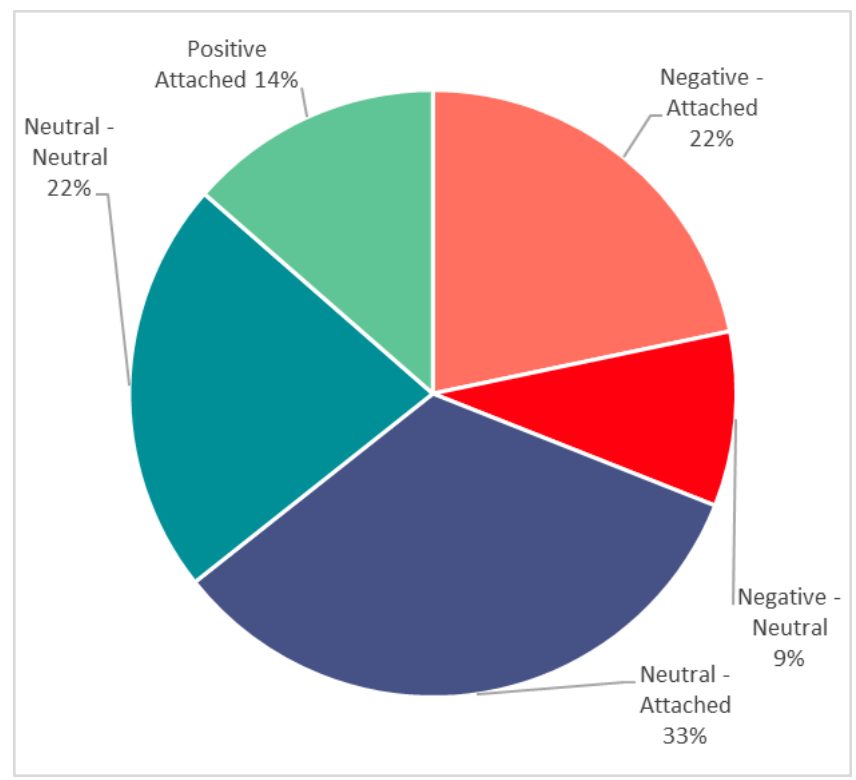

Figure 5: Share of types of regional EU identification in the EU as a whole. Source: Own elaboration on the basis of Eurobarometer data.

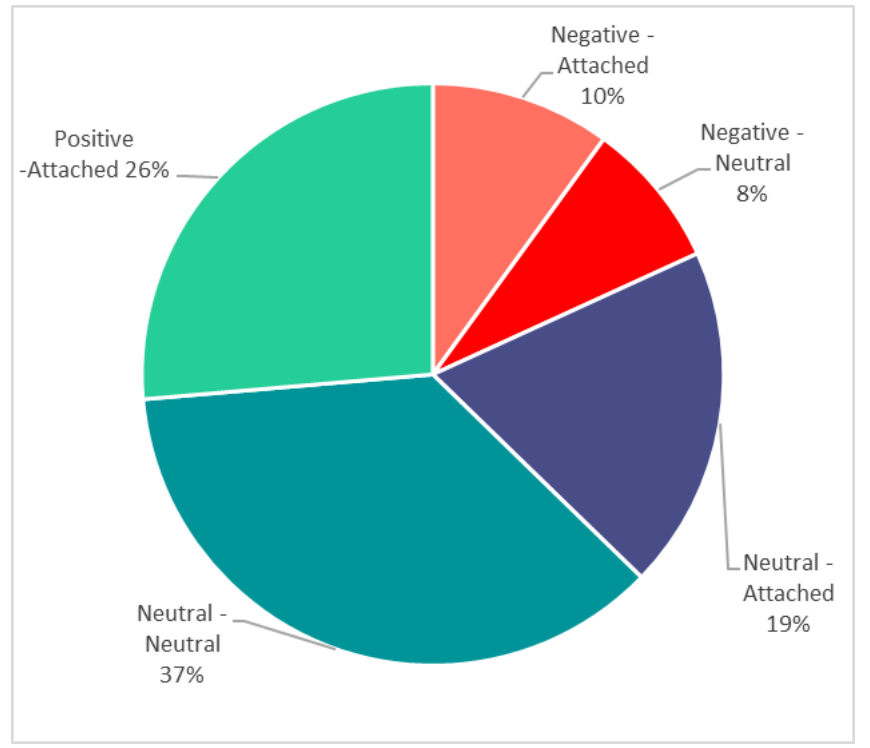

Figure 6: Share of types of regional EU identification in the Southern and Eastern European regions. Source: own elaboration on the basis of Eurobarometer data. 
to benefit from substantial funding under 'Less developed regions/Convergence' objective (e.g. Calabria and Sicily or Extremadura and Andalusia) remain either in the neutral-attached or neutral-neutral category. This means that EU identification in its evaluative dimension remains neutral, but varies from neutral to positive in the affective dimension. Therefore, it seems that EU cohesion policy has not generated much 'love' for the EU in the regions in which it has supported investment over many years and that other factors must be at play in determining citizens' views on the EU.

In the case of Greece, a country that has been a long-standing beneficiary of EU cohesion policy, with most of its regions falling under the 'Less developed regions/ Convergence' objective, it is striking that EU identification is predominantly negative (only Western Macedonia remains neutral-attached, Crete and Thessaly negativeattached, and the majority of regions negative-neutral,). The same applies to Cyprus, which is in the negative-neutral cluster. One can speculate that in the case of these two countries, negative EU identification may have little to do with cohesion policy. In fact, it most likely deteriorated in recent years due to the particularly acute effects of the economic crisis starting in 2008, the Eurozone tensions, and the EU-imposed austerity measures, which substantially impoverished the society and led to political and social unrest. Positive type regions cluster in some of the Eastern member states that currently benefit from an enormous inflow of EU funding, such as Poland and Romania. These two countries stand out amongst the Eastern EU Member States, by having the most regions in the positive-attached category. This seems to confirm that there is a relationship between the importance of EU cohesion funding for a given region, and a more positive outlook on the EU among its citizens. That being said, many of the regions that have benefited from substantial support from the EU cohesion policy, qualified under Convergence/Less developed or Phasing-out /Transition objectives, are not necessarily characterised by more positive EU identification. In countries like the Czech Republic, there is a greater diversity of types, with Northwest and Moravia-Silesia characterised by the most negative EU identification (negativeneutral), and the rest of the regions split between neutral-neutral type, where predominantly the image of the EU is neither good nor bad and people tend to be lukewarm in terms of their attachment to the EU, and negative-attached type, where negative views on the EU prevail, but citizens nonetheless tend to be attached to the European integration project.

Figures 7 and 8 illustrate the relationships between the size of cohesion funds allocation for a given region and its type with respect to EU identification. This relationship is not straightforward. However, some interesting observations can be made. Regions that are classified as positive-attached in the EU identification typology have a relatively high average size of allocation per capita in the 2007-2013 period-much higher than the neutral-attached and neutral-neutral, let alone negativeneutral. What is puzzling is that the average allocation is even higher in regions in the negative-neutral type. Considering the average size of allocation as a ratio of regional GDP, the relationship between positive EU identification and the amount of funding 
flowing into a given region is clearer. Regions in the positive-attached and neutralattached categories have the highest allocations in relation to their GDP, respectively $14.63 \%$ and $13.99 \%$, which contrasts with $11.96 \%$ for the negative-neutral type and more significantly with $3.5 \%$ in the negative-attached type.

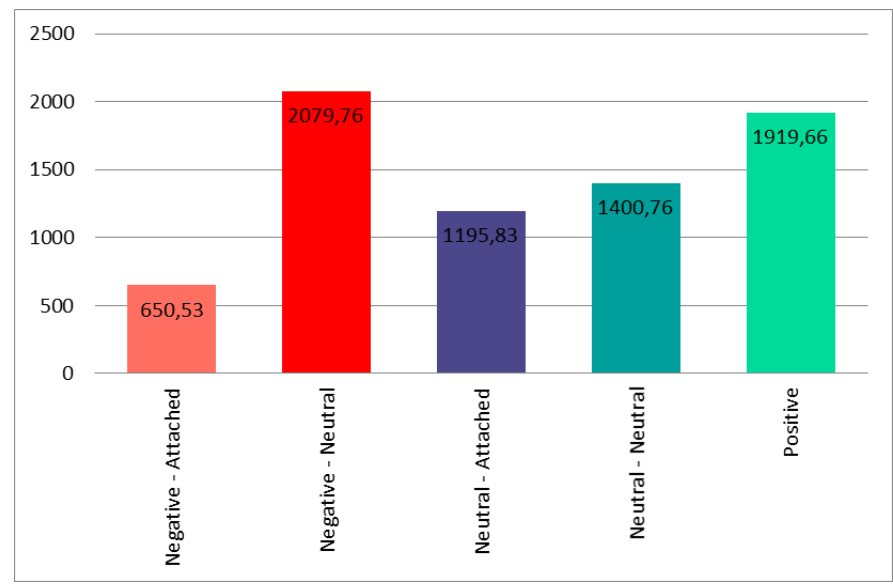

Figure 7: Allocation of EU Cohesion funding per capita (Euro) in Southern and Eastern European regions.

Source: Own elaboration on the basis of data from DG Region and Eurobarometer.

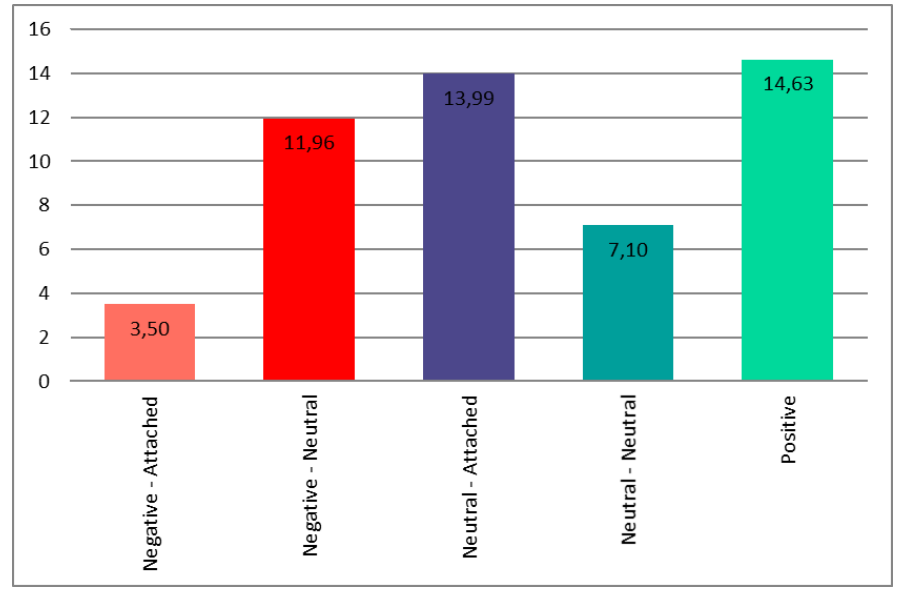

Figure 8: Allocation of EU Cohesion funding as a share (\%) of regional GDP in Southern and Eastern European regions.

Source: Own elaboration on the basis of data from DG Region and Eurobarometer. 
The most striking observation, perhaps, concerns the relationship between eligibility for EU cohesion policy, distinguishing between less developed regions, transition regions, and more developed regions, which is based mainly on GDP per capita in relation to EU average (see figures 9,10, 11). In fact, it is clear, as indicated in figures 9 and 10, that the positive-attached type is much more prominent among less developed regions (36\%), compared to more developed regions $(22 \%)$. The regions with a predominantly negative profile of EU identification (negative-neutral and negative-attached) add up to $7 \%$ of less developed regions, as compared to $28 \%$ of more developed regions. All in all, this seems to indicate that should there be a relationship between the intensity of EU cohesion policy's support for regions and EU identification, it is in the less developed regions, where most of EU funding is allocated. This relationship, however, would need to be explored in further research to shed more light on causality.

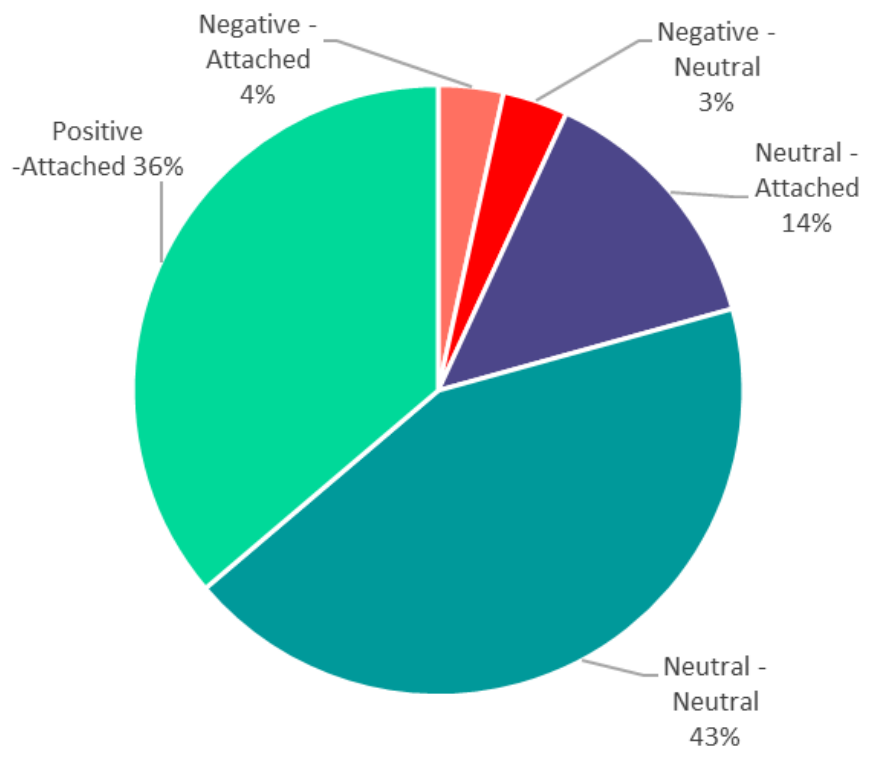

Figure 9: Distribution of EU identification types across the 'Less Developed' Southern and Eastern European regions.

Source: Own elaboration on the basis of data from DG Region and Eurobarometer. 


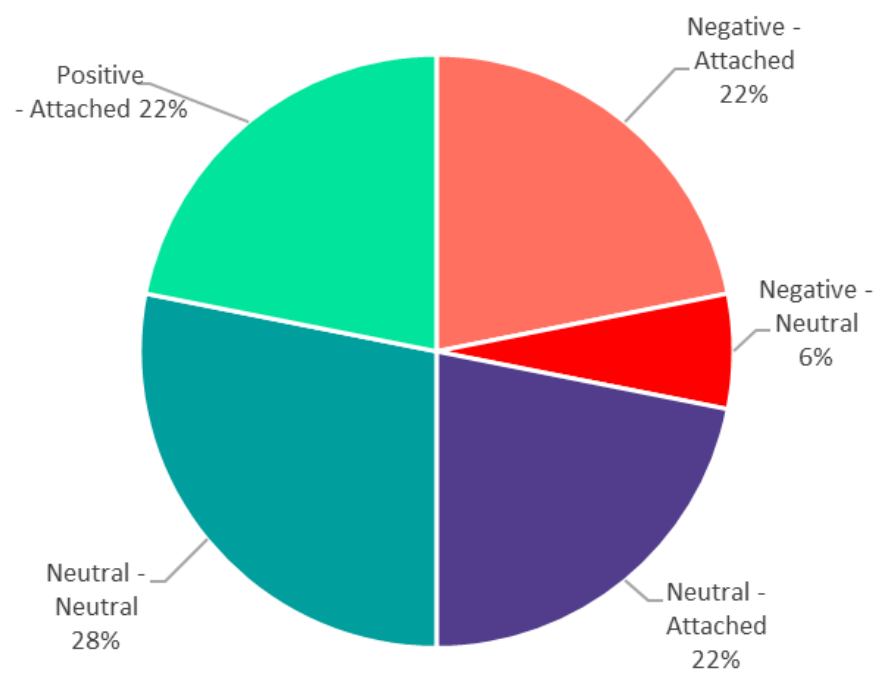

Figure 10: Distribution of EU identification types across the 'More Developed' Southern and Eastern European regions.

Source: Own elaboration on the basis of data from DG Region and Eurobarometer.

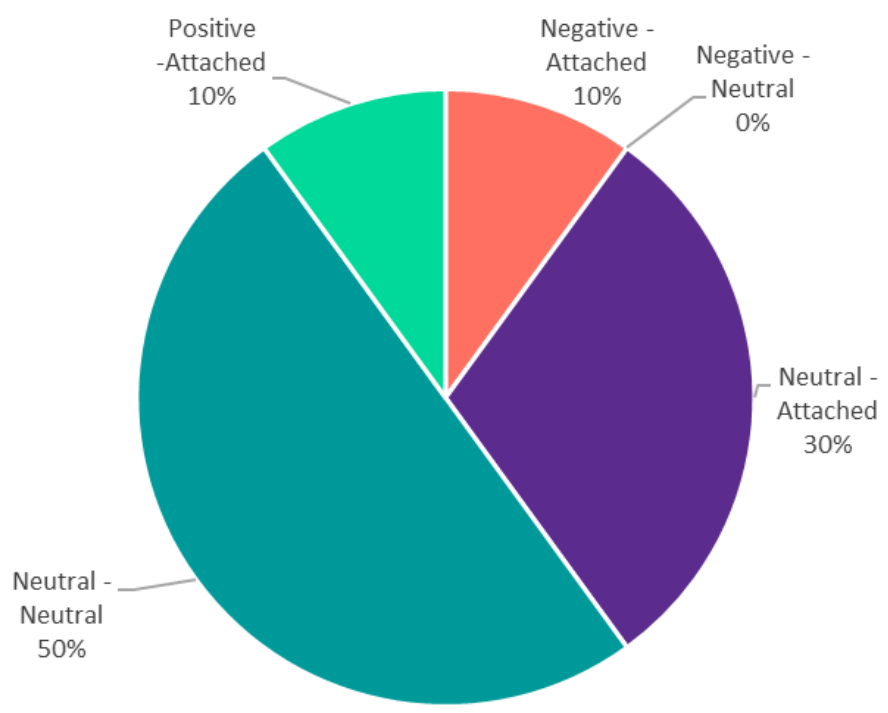

Figure 11: Distribution of EU identification types across 'Transition' Southern and Eastern European regions.

Source: Own elaboration on the basis of data from DG Region and Eurobarometer. 
Finally, the typology map (Figure 4) shows that there is a large variation in EU identification across border regions. In some border regions, citizens do not appear particularly positive about, or attached to, the EU, despite the fact that one could expect that the experience of interacting with countries across the border would strengthen EU identification. Many of the border regions-such as the Greek Eastern Macedonia and Thrace (bordering Bulgaria and Turkey) or the aforementioned Czech regions (Northwest, bordering Germany; and Moravia-Silesia bordering Poland and Slovakia)-fall under the negative-neutral category. This seems to put into question the claim that interactions across borders or transnational experience favour more positive attitudes towards the EU, as indicated in the literature. This may cast doubts on the claims on the positive impacts of territorial cooperation as part of EU cohesion policy on EU identification.

\subsection{Conclusion}

The typology presented in this study is an attempt to shed more light on the variation of EU identification at the regional level. Providing more clarity on the patterns of the evaluative and affective dimensions of EU identification across the extremely differentiated regions in Southern and Eastern European countries is a crucial first step towards understanding of the role of cohesion policy in shaping those patterns, which will require more in-depth statistical analysis probing of the determinants of the regional identification types.

The evidence in this study suggests that strong EU cohesion policy support in Eastern European regions seems to be related to positive EU identification, such as in Polish or Romanian regions. However, this is not always the case in the Southern Member States. In the south, a strong differentiation of regional types can be observed. In economically-lagging regions, which have benefitted from strong cohesion policy support, citizens are often less positive about the EU. The same applies to the Czech Republic, whose regions are particularly polarized in terms of EU identification, even though most of them are major beneficiaries of cohesion policy. These findings indicate that EU funding does not always tie into citizens' EU identification, which in turn suggests that other factors may be more important (e.g. socio-economic factors). This is particularly striking in the case of Greece, engulfed in economic crisis and coerced into an extremely controversial austerity programme by the EU, eroding positive identification despite substantial cohesion funding allocations to Greek regions.

The ostensibly weak relationship between EU funding and EU identification requires further study. At the same time, it points to several challenges for cohesion policy. In some regions, cohesion policy does not appear to have much impact on EU identification, or perhaps this impact is offset by other factors. This may be due to the 
policy making little difference on the lives of the citizens of those regions and/or the result of EU investment not being communicated well enough.

The observations in this study open up new avenues for further investigation into the determinants of the spatial patterns of EU identification across the European territory. What is the role of EU cohesion policy in this? Is it relevant or perhaps other policy or territorial, socio-economic or institutional factors are at play (e.g. size of allocation of EU funds, focus of spending on infrastructure or human resources, or the level of education of citizens)? Moreover, even in regions with a predominantly negative image of the EU, most citizens tend to identify with the EU or be neutral towards it. This dichotomy needs further investigation in future case study research, with particular attention to the cohesion policy support as a factor in shaping those perceptions. Finally, the limitation of this work is its focus on data spanning one year, thus future research could shed more light on the regional dimension of EU identification by comparing results from Eurobarometer surveys over the span of several years, providing more details about changing attitudes towards the EU over time.

\section{Acknowledgements}

The study was conducted as part of the COHESIFY project, funded by the European Union's Horizon 2020 Research and Innovation Programme, under Grant Agreement no. 693427. Research assistance was provided by Balázs Dukai (Delft University of Technology). Anna Frankowska (Old-Continent) assisted with the production of the maps.

\section{References}

Bellucci, P., Sanders, D., \& Serricchio, F. (2012). Explaining European Identity. In D. Sanders, P. Bellucci, G. Tóka, \& M. Torcal (Eds.), The Europeanization of National Polities?Citizenship and Support in a Post-Enlargement Union. Oxford: Oxford University Press.

Brinegar, A., Jolly, S., \& Kitschelt, H. (2004). Varieties of Capitalism and Political Divides over European Integration. In G. Marks \& M. Steenbergen (Eds.), European Integration and Political Conflict (pp. 68-89). Cambridge: Cambridge University Press.

Bruter, M. (2009). Time bomb? The dynamic effect of news and symbols on the political identity of European citizens. Comparative Political Studies, 42(12), 1498-1536.

Chacha, M. (2013). Regional attachment and support for European integration. European Union Politics, 14(2), 206-227.

Chalmers, A. W., \& Dellmuth, L. M. (2015). Fiscal redistribution and public support for European integration. European Union Politics, 16(3), 386-407. 
Citrin, J., \& Sides, J. (2004). More than nationals: how identity matters in the New Europe. In R. Herrman, T. Risse, \& M. Brewer (Eds.), Transnational Identities: Becoming European in the EU. Rowman \& Littlefield Publishers.

Dijkstra, L., Poelman, H., Rodríguez-Pose, A. (2019) The geography of EU discontent, Regional Studies, published online ahead of print. DOI: 10.1080/00343404.2019.1654603

Duch, R., \& Taylor, M. (1997) Economics and the Vulnerability of the Pan-European Institutions, Political Behaviour, 19(1), 65-80.

Duchesne, S., \& Frognier, A.-P. (1995). Is there a European identity? In O. Niedermayer \& R. Sinnott (Eds.), Public opinion and Internationalized Governance (pp. 193-226). Oxford: Oxford University Press.

Fligstein, N. (2008). Euroclash: The EU, European identity, and the future of Europe. Oxford University Press.

Fligstein, N. (2009). Who are the Europeans and how does this matter for policy? In J. T. Checkel \& P. J. Katzenstein (Eds.), European identity. Cambridge: Cambridge University Press.

Gore Jr., P. A. (2000). 11 - Cluster Analysis A2 - Tinsley, Howard E.A. In S. D. B. T.-H. of A. M. S. and M. M. Brown (Ed.) (pp. 297-321). San Diego: Academic Press. https://doi.org/http://dx.doi. org/10.1016/B978-012691360-6/50012-4

Hooghe, L., \& Marks, G. (2003). Unraveling the central state, but how? Types of multi-level governance. American Political Science Review, 97(2), 233-243.

Marks, G. (1999). Territorial Identities in the European Union. In J. J. Anderson (Ed.), Regional Integration and Democracy: Expanding on the European Experience. Lanham, MDRowman \& Littlefield.

Medrano, J. D., \& Gutiérrez, P. (2001). Nested identities: national and European identity in Spain. Ethnic and Racial Studies, 24(5), 753-778.

Mendez, C., \& Bachtler, J. (2016). European Identity and Citizen Attitudes to cohesion policy: What do we know? H2020 COHESIFY Project Work Package 2 - Task2.1: Output 2.1. Retrieved from http:// www.cohesify.eu/downloads/Cohesify_Research_Paper1.pdf

Osterloh, S. (2011). Can regional transfers buy public support? Evidence from EU structural policy (Working Papers No. 16). Vienna.

Smętkowski, M., \& Dąbrowski, M. (2019). Economic crisis, Cohesion Policy and the eroding image of the European Union at the regional level. Regional Science Policy \& Practice, 11(4), 713-732.

Yannis, P., Dimitris, K., \& Panagiotis, P. (2014). Economic crisis and regional resilience: detecting the "geographical footprint" of economic crisis in Greece. Regional Science Policy \& Practice, 6(2), 121-141. https://doi.org/10.1111/rsp3.12032 